\title{
Dynamic Changes of the Frequency of Classic and Inflammatory Monocytes Subsets and Natural Killer Cells in Chronic Hepatitis C Patients Treated by Direct-Acting Antiviral Agents
}

\author{
Gang Ning, Yi-ting Li, You-ming Chen, Ying Zhang, Ying-fu Zeng, and Chao-shuang Lin \\ Department of Infectious Diseases, The Third Affiliated Hospital of Sun Yat-Sen University, Guangzhou 510630, China \\ Correspondence should be addressed to Chao-shuang Lin; shuangss@21cn.com
}

Received 11 January 2017; Accepted 14 February 2017; Published 8 May 2017

Academic Editor: José L. Mauriz

Copyright (c) 2017 Gang Ning et al. This is an open access article distributed under the Creative Commons Attribution License, which permits unrestricted use, distribution, and reproduction in any medium, provided the original work is properly cited.

\begin{abstract}
Objective. Up to now, little was known about the immunological changes of chronic hepatitis $\mathrm{C}$ (CHC) patients treated with directacting antiviral agents (DAAs); we try to explore the effect of DAAs on the frequency of monocytes, NK cells, and cytokines that promote their activation. Methods. 15 treatment-naive $\mathrm{CHC}$ patients and 10 healthy controls were recruited. Patients were examined before DAAs therapy $(0 \mathrm{w})$ and at week $4(4 \mathrm{w})$ and week $12(12 \mathrm{w})$ of therapy. Percentage of monocytes and NK cells of the peripheral blood was analyzed by flow cytometry. Serum cytokines IL-12, IL-18, CXCL10, CXCL11, sCD14, and sCD163 were measured by enzyme linked immunosorbent assay. Results. The frequency of $\mathrm{CD}^{-} \mathrm{CD}_{16}{ }^{+} \mathrm{CD} 56^{+} \mathrm{NK}$ cells and classic $\mathrm{CD} 14^{++} \mathrm{CD} 16^{-}$ monocytes decreased, while CD14 ${ }^{+} \mathrm{CD} 16^{+}$monocytes and cytokines IL-12, IL-18, CXCL10, CXCL11, sCD14, and sCD163 increased at $0 \mathrm{w}$ compared to healthy controls. During DAAs treatment, the decreased NK cells and classic monocytes gradually increased to normal levels; the increased inflammatory monocytes and cytokines IL-12 and CXCL11 decreased to normal levels, but the increased cytokines IL-18, CXCL10, sCD14, and sCD163 still remained at high levels at $12 \mathrm{w}$ though they decreased rapidly from 0 w. Conclusion. Our results showed that DAAs treatment attenuated the activation of monocytes and NK cells in CHC patients. Trial registration number is NCT03063723.
\end{abstract}

\section{Introduction}

Treatment of hepatitis C virus (HCV) infection has greatly advanced with the advent of the new direct-acting antivirals (DAAs) in the past 5 years. More than $90 \%$ of chronic hepatitis $\mathrm{C}(\mathrm{CHC})$ patients could achieve a sustained viral response (SVR) using DAAs after 12 weeks of treatment [1-3]. Among all the DAAs regimens, daclatasvir/sofosbuvir and ledipasvir/ sofosbuvir are recommended for all of the genotypes except for patients with genotype 3 infection with cirrhosis by WHO. Now, these two DAAs regimens are included in voluntary licensing agreements signed between the originator companies and generics companies. In fact, daclatasvir/sofosbuvir and ledipasvir/sofosbuvir are already available in generic formulations in some countries. The introduction of generic formulations results in lower prices. It has been report reported that the price for a 12-week regimen of generic sofosbuvir would be less than US\$ 500/patient in India, and no doubt, the wide-scale implementation of HCV treatment will be facilitated by this rapid reduction in the price of daclatasvir/sofosbuvir and ledipasvir/sofosbuvir [4].

Previous studies have shown that suppression or eradication of HCV infection has been related to a reduced risk of developing hepatocellular carcinoma (HCC) and improved outcomes in CHC patients [5-7]. In one recent meta-analysis study, the estimated relative risk of HCC development in CHC patients with all stages of fibrosis who achieved SVR by interferon therapy was 0.24 , meaning that interferon therapy was able to reduce the risk of HCC occurrence by $76 \%$ [8]. Considering high rates of SVR achieved in patients with $\mathrm{CHC}$ treated with DAAs, it is reasonable to raise the hope of a drastic decline in HCC occurrence and even a decline in HCC recurrence.

Surprisingly and unexpectedly, increased aggressiveness and high rates of HCC recurrence (28\% (16/58) and 29\% 
(17/59), resp.) have been reported in patients who cleared $\mathrm{HCV}$ with DAAs after achieving a complete response to resection or local ablation within only 6 months of therapy $[9,10]$. The authors hypothesized that the rapid eradication of HCV and control of liver inflammation would impact antitumoral immune control, which in turn might contribute to the neoplastic cells proliferation. Conversely, three independent prospective French cohorts failed to reveal an increased risk of HCC recurrence after DAAs treatment in $\mathrm{CHC}$ patients after receiving curative cancer treatments [11]. The conflicting results have raised commentaries and criticism which are a controversial issue with potential clinical implications [12$14]$.

Although the impact of DAAs treatment on the rate of HCC occurrence or recurrence still remain unclear, it would be more important to pay attention to the immunological changes of CHC patients treated with DAAs. Until now, however, only a few studies were performed to explore the changes of immunological milieu of CHC patients during DAAs treatment [15-17]. Hengst et al. and Carlin et al. explored the effect of DAAs treatment on the inflammatory cytokines and chemokines of CHC patients; they found that DAAs-induced HCV clearance could only partially restore the altered inflammatory mediators $[15,16]$. Martin et al. found that DAAs therapy improved the proliferation of HCV-specific T cells, but it still remained unknown to which extent cytokine production of HCV-specific T cells could be recovered [17]. In spite of this, little is known about the influence of DAAs treatment on monocytes.

Here in our study, we aim to explore the effect of antiviral treatment of $\mathrm{CHC}$ patients with DAAs on the frequency of monocytes (classic $\mathrm{CD} 14^{++} \mathrm{CD} 16^{-}$monocytes and inflammatory $\mathrm{CD}_{1} 4^{+} \mathrm{CD} 16^{+}$monocytes) [18], NK cells $\left(\mathrm{CD}^{-} \mathrm{CD}^{+} 6^{+} \mathrm{CD} 56^{+}\right)$[19], and cytokines IL-12, IL-18, CXCL10, and CXCL11, which are necessary to activation of NK cells, and soluble CD14 (sCD14) and soluble CD163 (sCD163), which reflect monocytes activation.

\section{Material and Methods}

2.1. Patients and Samples. 15 treatment-naive CHC patients (6 males and 9 females) and 10 healthy controls (6 males and 4 females) were recruited at the third affiliated hospital of Sun Yat-Sen university (Guangzhou, China) from January 2016 to November 2016. The mean age of CHC patients was $48.06 \pm 3.82$ years and the mean age of healthy controls was $27.30 \pm 3.40$ years. Eight $\mathrm{CHC}$ patients were treated with sofosbuvir (400 mg, qd)/ledipasvir ( $90 \mathrm{mg}$, qd) for 12 weeks and $7 \mathrm{CHC}$ patients were treated with sofosbuvir $(400 \mathrm{mg}$, qd)/daclatasvir (60 mg, qd) for 12 weeks. Basic characteristics of all the subjects were shown in Table 1. Patients coinfected with HAV, HBV, HDV, HEV, and human immunodeficiency virus were excluded. Besides, pregnant patients or patients with psychiatric disorder were also excluded. This study protocol was approved by the Ethics Review Board of the third affiliated hospital of Sun Yat-Sen university and written informed consent was obtained from the patients before enrollment.
TABLE 1: Basic characteristics of subjects.

\begin{tabular}{|c|c|c|}
\hline Index & CHC Patients & $\begin{array}{l}\text { Healthy } \\
\text { Controls }\end{array}$ \\
\hline Number & 15 & 10 \\
\hline Age (y) & $48.06 \pm 3.82$ & $27.30 \pm 3.40$ \\
\hline Gender (M/f) & $6 / 9$ & $6 / 4$ \\
\hline $\operatorname{ALT}(\mathrm{U} / \mathrm{L}$, mean $\pm \mathrm{SE})$ & $49.29 \pm 7.47$ & NA \\
\hline $\mathrm{AST}(\mathrm{U} / \mathrm{L}$, mean $\pm \mathrm{SE})$ & $52.78 \pm 9.39$ & NA \\
\hline $\begin{array}{l}\text { HCV-RNA } \\
(\log 10 \mathrm{IU} / \mathrm{mL})\end{array}$ & $6.02 \pm 0.30$ & NA \\
\hline HCV-RNA genotype & $\begin{array}{c}\mathrm{lb}(42 \%) / 6 \mathrm{a}(30 \%) / 2 \mathrm{a} \\
(28 \%)\end{array}$ & NA \\
\hline Treatment & $\begin{array}{l}\text { Sofosbuvir + ledipasvir } \\
(8 / 15), \text { sofosbuvir + } \\
\text { daclatasvir }(7 / 15)\end{array}$ & NA \\
\hline RVR/SVR & $100 \%$ & NA \\
\hline
\end{tabular}

2.2. Peripheral Blood Mononuclear Cells (PBMC) Isolation and Storage. All CHC patients were monitored before, during and after DAAs treatment at the out patients clinic of department of infectious diseases. Peripheral blood samples $(10 \mathrm{~mL})$ were collected from CHC patients before therapy $(0 \mathrm{w})$, at 4 weeks $(4 \mathrm{w})$, and at the end of treatment $(12 \mathrm{w})$ and from healthy controls with EDTA anticoagulation tubes (Invitrogen, BD). Then PBMC were isolated from peripheral blood samples and cryopreserved at $-80^{\circ} \mathrm{C}$ and 72 hours later were transferred to the liquid nitrogen as previously described [20].

2.3. Measurement of Viral Load, ALT, and AST. Serum HCV RNA was quantified by COBAS Taqman assay (Roche Diagnostic, Basel, Switzerland). ALT and AST were measured with Hitachi 7170 automatic biochemistry analyzer in the laboratory center of the third affiliated hospital.

2.4. Flow Cytometry. In order to examine the phenotype and frequency of classic $\mathrm{CD}_{14}{ }^{++} \mathrm{CD} 16^{-}$monocytes, nonclassic/intermediate $\mathrm{CD}_{14}{ }^{+} \mathrm{CD} 16^{+}$monocytes and $\mathrm{CD}^{-} \mathrm{CD} 16^{+} \mathrm{CD} 6^{+} \mathrm{NK}$ cells, relevant labeled multicolor fluorescence anti-human monoclonal antibodies (mAbs) purchased from eBioscience (San Diego, CA, US) were used for surface staining: anti-CD14-FITC, anti-CD16PERCP-Cy7, anti-CD3-PERCP, anti-CD56-PERCP-Cy7, and anti-CD16-PE. PBMC was first thawed and then resuspended in flow staining buffer (PBS plus 1\% FBS); after being washed twice, $\mathrm{PBMC}$ was resuspended again and incubated with the above labeled multicolor fluorescence anti-human monoclonal antibodies. Then the stained PBMC was washed with flow staining buffer and centrifuged. Finally, the stained PBMC were diluted and analyzed on a flow cytometer (BD LSR II) (BD Biosciences). Data was acquired as the fraction of labeled cells within a cell gate set for 20,000 events. The detailed procession was described in our previous study [20]. 
2.5. Enzyme Linked Immunosorbent Assay (ELISA). Measurement of serum IL-12p70, IL-18, CXCL10, CXCL11, sCD14, and sCD163 were performed with the ProcartaPlex ${ }^{\mathrm{TM}}$ Multiplex Immunoassay (eBioscience) according to the manufacturer's protocol using a BD FACSCanto ${ }^{\mathrm{TM}}$ II flow cytometer. The Flowlogic ${ }^{\mathrm{TM}}$ and Beadlogic $\mathrm{C}^{\mathrm{TM}}$ software (Inivai Technologies, Mentone, Vic., Australia) were used for data analysis.

2.6. Statistical Analysis. Normally distributed quantitative data were presented as mean \pm standard, while the nonnormally distributed data were expressed as interquartile range. 1-way ANOVA test was used for assessment of the differences among values during the course of treatment, and Mann-Whitney $U$ tests or unpaired $t$-test was used for comparison between patients and healthy controls. All data were analyzed by SPSS Statistics 20 and all figures were made by Prizm5.0 statistical analysis software (GraphPad Software). $P$ value less than 0.05 was considered to be statistically significant.

\section{Results}

3.1. Effect of DAAs Treatment on HCV Viremia and Liver Inflammation. All 15 treatment-naive $\mathrm{CHC}$ patients had achieved a rapid virological response (RVR), defined as undetectable HCV RNA $<15 \mathrm{U} / \mathrm{mL}$, at the first 4 weeks of sofosbuvir/ledipasvir or sofosbuvir/daclatasvir treatment (Table 1). What is more, none of them experienced virological breakthrough at week 12. Similarly, serum ALT and AST levels had also decreased significantly within the 4 weeks of DAAs treatment and none experienced ALT or AST rebound.

3.2. Dynamic Changes of the Frequency of Monocytes Subsets and Natural Killer Cells during DAAs Treatment. We used flow cytometry to analyze the dynamic changes of the frequency of monocytes subsets and NK cells in the peripheral blood of CHC patients during DAAs treatment, and representative flow cytometry plots of $\mathrm{CD} 14^{++} \mathrm{CD}^{-} 6^{-}$monocyte, $\mathrm{CD} 14^{+} \mathrm{CD} 16^{+}$monocyte, $\mathrm{CD}^{-} \mathrm{CD}^{+} 6^{+} \mathrm{CD} 56^{+} \mathrm{NK}$ cells were presented in Figure 1(a). The frequency of classic $\mathrm{CD}_{14}{ }^{++} \mathrm{CD} 16^{-}$monocytes was less than healthy controls at baseline $(0 \mathrm{w})(59.14 \pm 0.54 \%$ versus $72.75 \pm 1.31 \%, P<0.001)$ and then gradually increased to HC levels $(71.54 \pm 2.99 \%$ versus $72.75 \pm 1.31 \%, P>0.05)$ during DAAs treatment $(12 \mathrm{w})$. Conversely, the levels of inflammatory $\mathrm{CD} 14^{+} \mathrm{CD} 16^{+}$monocyte were higher than $\mathrm{HC}$ levels at $0 \mathrm{w}(18.49 \pm 1.54 \%$ versus $10.65 \pm 0.83 \%, P<0.0001)$ but then rapidly decreased to normal levels of $\mathrm{HC}(12.42 \pm 1.60 \%$ versus $10.65 \pm 0.83, P>0.05)$ at $12 \mathrm{w}$. The changes of the frequency of $\mathrm{CD} 3^{-} \mathrm{CD} 16^{+} \mathrm{CD} 56^{+}$ $\mathrm{NK}$ cells were similar to classic $\mathrm{CD} 14^{++} \mathrm{CD} 16^{-}$monocytes. The frequency of $\mathrm{CD}^{-} \mathrm{CD} 16^{+} \mathrm{CD} 56^{+} \mathrm{NK}$ cells decreased compared to that of $\mathrm{HC}$ level at baseline $(13.29 \pm 0.85 \%$ versus $18.72 \pm 1.91 \%, P<0.001)$, and after treatment with DAAs, it gradually increased to normal levels of $\mathrm{HC}$ at $12 \mathrm{w}(14.44 \pm$ $1.60 \%$ versus $18.72 \pm 1.91, P>0.05$ ) (Figures $1(\mathrm{~b})-1(\mathrm{~d})$ ). The detailed information about dynamic changes of the frequency of monocytes subsets and natural killer cells was shown in Table 2.
3.3. Kinetics of the Levels of Serum sCD14, sCD163, IL12, IL-18, CXCL10, and CXCL11 during DAAs Treatment. To further explored the effect of DAAs treatment on the function of monocytes subsets and natural killer cells, we next analyzed the kinetics of the levels of serum sCD14 and sCD163, which reflected monocytes activation and serum IL-12, IL-18, CXCL10, and CXCL11, which promoted NK cells activation during DAAs treatment. Consistent with the above results, all the levels of serum sCD14, sCD163, IL12, IL-18, CXCL10, and CXCL11 were higher than that of $\mathrm{HC}$ at baseline, and during DAAs treatment, sCD14, serum sCD163, and CXCL10 decreased rapidly while IL-12, IL-18, and CXCL11 decreased gradually. However, plasma IL-12 and CXCL11 levels decreased to normal levels of HC, but serum sCD14, sCD163, CXCL10, and IL-18 still remained at high levels (Figures 2(a)-2(f)). The detailed information about dynamic changes of the levels of serum sCD14, sCD163, IL12, IL-18, CXCL10, and CXCL11 during DAAs treatment was shown in Table 2.

\section{Discussion}

The development of highly effective interferon-free DAAs regiments has revolutionized the treatment of $\mathrm{HCV}$ infection and may thus lead to complete eradication of HCV worldwide. However, little was known about the immunological changes of CHC patients during DAAs treatment. So, here in our study, we explored the impact of DAAs treatment on the frequency of monocytes subsets and NK cells.

NK cells are the main innate immune cells of the liver in healthy human and their frequency decreases in the blood but increases in the liver in chronic HCV infection [21]. $\mathrm{NK}$ cells from $\mathrm{CHC}$ patients are activated by low levels of $\mathrm{HCV}$-induced interferon- $\alpha$, and they expressed increased cytotoxic functions and TNF-related apoptosis-inducing ligand (TRAIL) but decreased antiviral cytokine interferon- $\gamma$ production. Besides, these NK cells also expressed higher levels of activated receptors, such as NKp30, NKp44, NKp46, NKG2C, NKG2D, and CD122, and inhibitory receptor NKG2A than those from healthy controls [22, 23]. Previous studies had explored the effect of interferon therapy on the NK cells. It has been shown that CHC patients with SVR by interferon therapy exhibited greater levels of $\mathrm{NK}$ cell degranulation and enhanced NK cytotoxicity and thus, NK cell responses can be used as an indicator of a patient's interferon responsiveness [24, 25]. Recently, Spaan et al. explored the effect of DAAs therapy on NK cells; they found that DAAs therapy increased the percentage of $\mathrm{CD} 3{ }^{+} \mathrm{CD} 56^{\mathrm{dim}} \mathrm{NK}$ cells, downregulated surface NKp30, NKp46, and NKG2A expression on NK cells to a phenotype resembling healthy controls, and decreased NK cell-related cytokines (IL-12, IL18) and TRAIL expression of CHC patients during DAAs treatment [26]. In line with Spaan's study, we also found that NK cells frequency of peripheral blood decreased before DAAs treatment but then gradually increased to normal levels of healthy controls. The changes of serum IL-12, IL18, CXCL10, and CXCL11 were consistent with the changes of NK cells. They were higher than healthy controls at baseline but then diminished during DAAs treatment. IL-12, IL-18, 


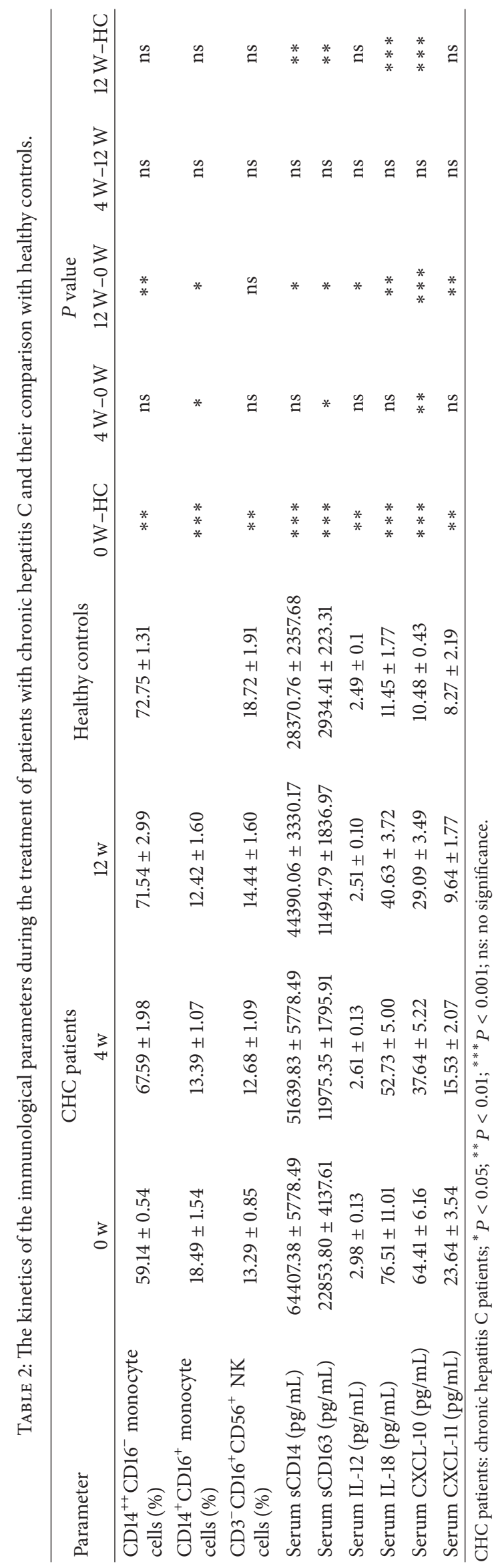



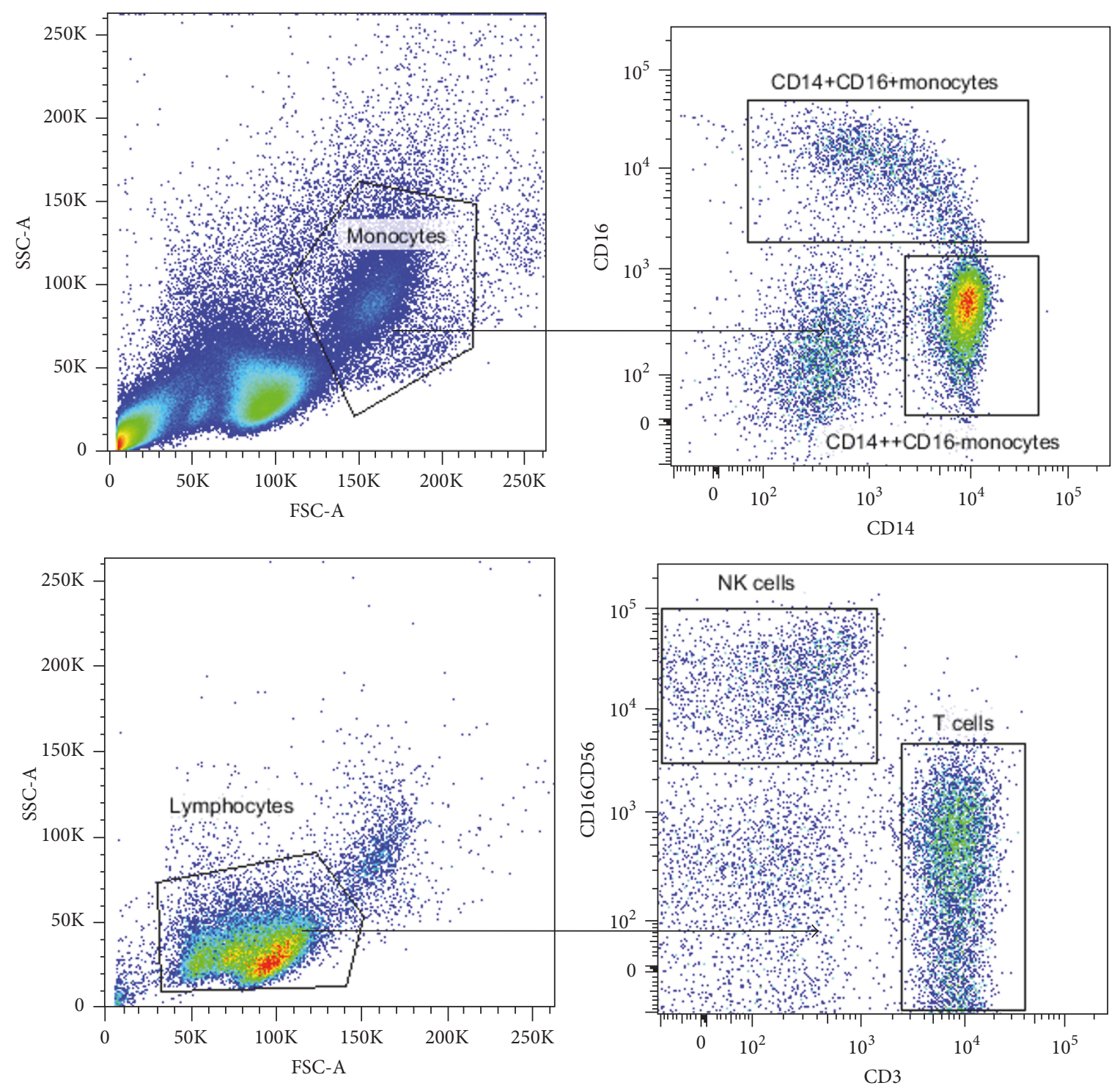

(a)

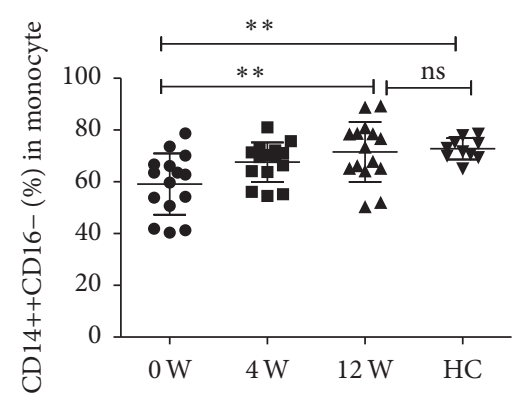

(b)

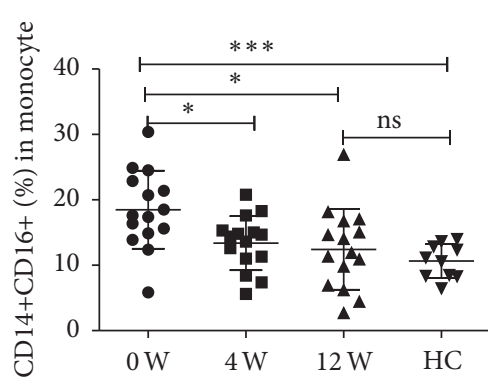

(c)

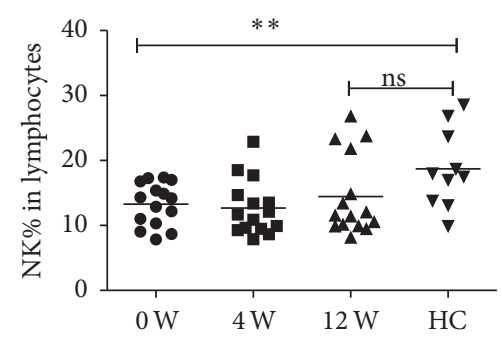

(d)

FIGURE 1: Dynamic changes of the frequency of monocytes subsets and natural killer cells during DAAs treatment. (a) Representative flow cytometry plots of $\mathrm{CD} 14^{++} \mathrm{CD} 16^{-}$monocytes, $\mathrm{CD} 14^{+} \mathrm{CD} 16^{+}$monocytes, and $\mathrm{CD}^{-} \mathrm{CD} 16^{+} \mathrm{CD} 56^{+} \mathrm{NK}$ cells; (b) dynamic changes of the frequency of $\mathrm{CD} 14^{++} \mathrm{CD} 16^{-}$monocytes; (c) dynamic changes of the frequency of $\mathrm{CD} 14^{+} \mathrm{CD} 16^{+}$monocytes; (d) dynamic changes of the frequency of $\mathrm{CD}^{-} \mathrm{CD} 16^{+} \mathrm{CD} 56^{+} \mathrm{NK}$ cells. ${ }^{*} p<0.05 ;{ }^{* *} p<0.01 ;{ }^{* * *} p<0.001$. 


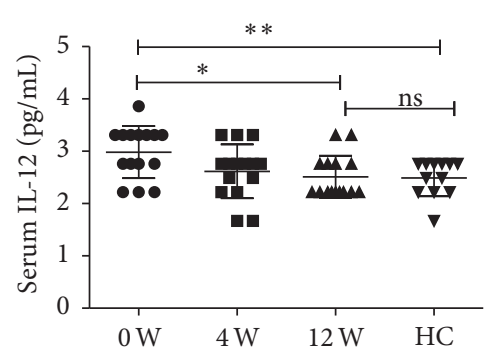

(a)

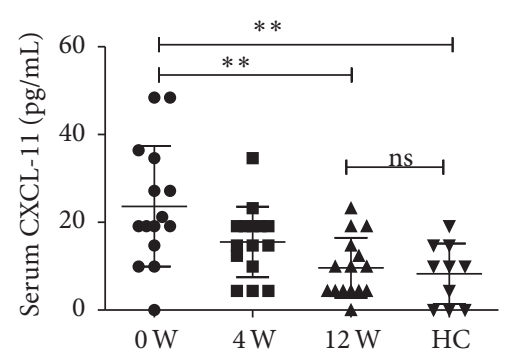

(d)

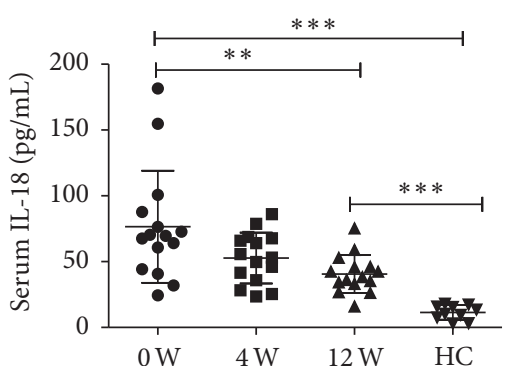

(b)

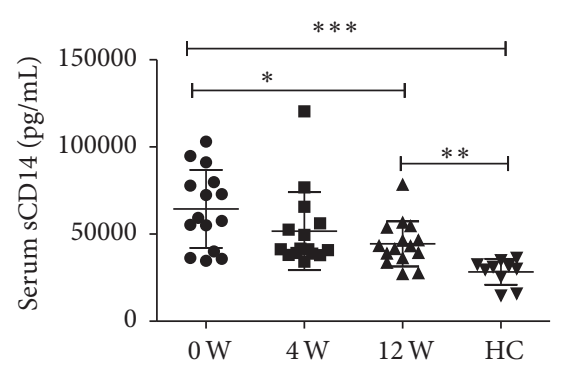

(e)

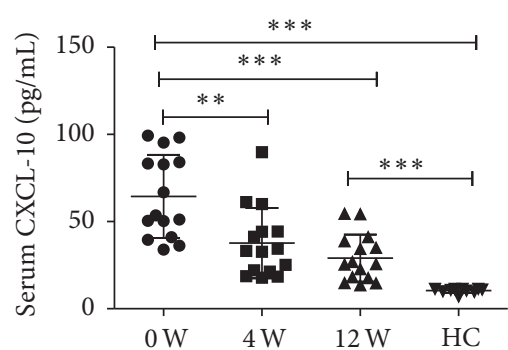

(c)

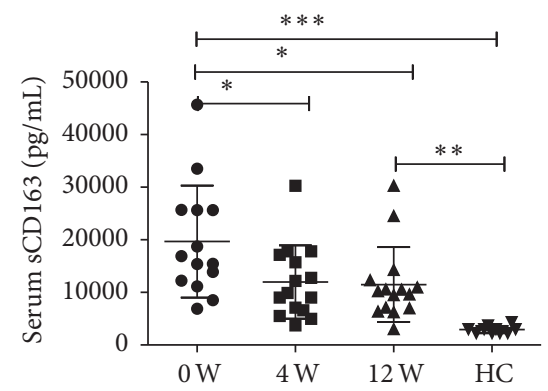

(f)

Figure 2: Kinetics of the levels of serum cytokines during DAAs treatment. (a) Dynamic changes of the levels of IL-12; (b) dynamic changes of the levels of IL-18; (c) dynamic changes of the levels of CXCL10; (d) dynamic changes of the levels of CXCL11; (e) dynamic changes of the levels of sCD14; (f) dynamic changes of the levels of sCD163. ${ }^{*} p<0.05 ;{ }^{* *} p<0.01$; ${ }^{* * *} p<0.001$.

CXCL10, and CXCL11 are important for NK cells activation. IL-12 and IL-18 could promote interferon- $\gamma$ production of NK cells, and CXCL10 and CXCL11 could activate NK cells to express higher levels of STAT1 and pSTAT1, which are an essential part of signaling downstream of the interferon receptor [27]. Serti et al. demonstrated that DAAs treatment decreased serum levels of CXCL10 and CXCL11, leading to decreased expression of the STAT1 and pSTAT1 of NK cells, and the decreased expression of STAT1 and pSTAT1 was associated with normalization of NK cells phenotype observed in Spaan's study [26, 27]. Furthermore, Serti et al. had also found that DAAs treatment-induced normalization of NK cells phenotype and function may follow a hierarchy. Briefly speaking, significant decrease in HCV titer by DAAs treatment first induced decrease in activation surface HLADR expression of NK cells and then reversed the alter cytokine production by NK cells and last normalized the alter cytotoxicity of NK cells.

Similar to NK cells, monocytes are also an important part of the first line of defense against HCV infection. During $\mathrm{HCV}$ infection, peripheral blood monocytes are attracted to the liver and differentiate into macrophages and Kupffer cells. Monocytes/macrophages play an important role in initiating the adaptive immune response and influencing the Th1/Th2 polarization by producing excessive inflammatory and immune-modulatory cytokines, such as IL-10 and IL12. These cytokines may also impair the ability of antigen presenting cells to activate naive $\mathrm{T}$ cells and thus help to HCV replication and establish persistent infection [28]. Zheng et al. found that circulating $\mathrm{CD} 14^{++} \mathrm{CD} 16^{-}$monocytes decreased while $\mathrm{CD} 14^{+} \mathrm{CD} 16^{+}$monocytes increased in $\mathrm{CHC}$ patients when compared to $\mathrm{HCV}$ spontaneous resolved and healthy controls, and $\mathrm{CD} 14^{+} \mathrm{CD} 16^{+}$monocytes were negatively correlated with HCV viremia but PD-L1/CD86 ratio in $\mathrm{CD} 14^{+} \mathrm{CD} 16^{+}$monocytes was closely correlated with HCV viremia [29]. Similarly, in our study, we also found that $\mathrm{CD} 14^{++} \mathrm{CD}^{-} 6^{-}$monocytes decreased but $\mathrm{CD} 14^{+} \mathrm{CD} 16^{+}$ monocytes increased at baseline in CHC patients. Furthermore, we also found that $\mathrm{CD} 14^{++} \mathrm{CD} 16^{-}$monocytes increased to levels of healthy controls while $\mathrm{CD} 14^{+} \mathrm{CD} 16^{+}$monocytes decreased to the levels which was similar to healthy controls during DAAs treatment. Up to now, however, little is known about the effect of DAAs treatment on the function of monocytes. In our study, we found that the changes of serum $\mathrm{sCD} 14$ and $\mathrm{sCD} 16$ which reflected the monocytes activation were similar to the changes of $\mathrm{CD} 14^{+} \mathrm{CD} 16^{+}$ monocytes, indirectly indicating a decrease in the monocyte activation. Recently, Bility et al. found that HCV-induced M2 macrophages activation was associated with liver fibrosis during HCV infection and supernatant of HCV-infected cells could polarize human monocytes to a M2-like phenotype. What is more, DAAs treatment attenuated M2 macrophages activation and associated liver fibrosis [30]. Interestingly, Gambato et al. found that DAAs treatment did not have obvious effect on the phagocytic and oxidative burst capacity of monocytes in patients with advanced liver fibrosis [31]. Therefore, further studies are needed to explore the impact of DAAs treatment on the changes of the function of monocytes.

There are several limitations in our study. First, the impact of DAAs treatment on the frequency of monocytes and NK cells was only evaluated at the first 12 weeks of treatment and therefore, the long-term effects still remain unknown. However, we would continue the study and explore the longterm effects by DAAs treatment. Second, $\mathrm{CHC}$ patients were 
not treated with the same DAAs regimen and the HCV genotypes were different; this may have an impact on our results. Finally, we did not evaluate the functional status of circulating monocytes and NK cells which could have been associated with the observed decrease in serum sCD14, sCD163, IL-12, IL-18, CXCL10, and CXCL11.

In conclusion, our results show that DAAs treatment attenuated the activation of monocytes and NK cells in $\mathrm{CHC}$ patients during DAAs treatment, indicated by decreased levels of sCD14, sCD163, IL-12, IL-18, CXCL10, and CXCL11 and normalization of the frequency of monocytes and $\mathrm{NK}$ cells, but the effect of DAAs treatment on their function still needs further research.

\section{Abbreviations}

HCV: Hepatitis C virus

DAAs: Direct-acting antivirals

CHC: Chronic hepatitis C

SVR: Sustained viral response

HCC: Hepatocellular carcinoma

RVR: Rapid virological response

TRAIL: TNF-related apoptosis-inducing ligand.

\section{Conflicts of Interest}

The authors declare no conflicts of interest.

\section{Acknowledgments}

This research is supported by grants of National Natural Science Foundation of China (Grant no. 31370907). The authors are grateful to the patients for their participation in this study.

\section{References}

[1] S. A. Alqahtani, N. Afdhal, S. Zeuzem et al., "Safety and tolerability of ledipasvir/sofosbuvir with and without ribavirin in patients with chronic hepatitis C Virus genotype 1 infection: analysis of phase III ION trials," Hepatology, vol. 62, no. 1, pp. 25-30, 2015.

[2] E. Lawitz, M. Makara, U. S. Akarca et al., "Efficacy and safety of ombitasvir, paritaprevir, and ritonavir in an open-label study of patients with genotype $1 \mathrm{~b}$ chronic hepatitis $\mathrm{C}$ virus infection with and without cirrhosis," Gastroenterology, vol. 149, no. 4, pp. 971-980.e1, 2015.

[3] K. R. Reddy, M. Bourlière, M. Sulkowski et al., "Ledipasvir and sofosbuvir in patients with genotype 1 hepatitis $\mathrm{C}$ virus infection and compensated cirrhosis: an integrated safety and efficacy analysis," Hepatology, vol. 62, no. 1, pp. 79-86, 2015.

[4] WHO, Guidelines for the Screening, Care and Treatment of Persons with Chronic Hepatitis C Infection Updated Version, World Health Organization, 2016.

[5] H. B. El-Serag, F. Kanwal, P. Richardson, and J. Kramer, "Risk of hepatocellular carcinoma after sustained virologic response in veterans with $\mathrm{HCV}$-infection," Hepatology, vol. 64, no. 1, pp. 130-137, 2016.

[6] A. J. van der Meer, B. J. Veldt, J. J. Feld et al., "Association between sustained virological response and all-cause mortality among patients with chronic hepatitis $\mathrm{C}$ and advanced hepatic fibrosis," The Journal of the American Medical Association, vol. 308, no. 24, pp. 2584-2593, 2012.

[7] M. Manns, D. Samuel, E. J. Gane et al., "Ledipasvir and sofosbuvir plus ribavirin in patients with genotype 1 or 4 hepatitis $C$ virus infection and advanced liver disease: a multicentre, openlabel, randomised, phase 2 trial," The Lancet Infectious Diseases, vol. 16, no. 6, pp. 685-697, 2016.

[8] R. L. Morgan, B. Baack, B. D. Smith, A. Yartel, M. Pitasi, and Y. Falck-Ytter, "Eradication of hepatitis $\mathrm{C}$ virus infection and the development of hepatocellular carcinoma: a meta-analysis of observational studies," Annals of Internal Medicine, vol. 158, no. 5, part 1, pp. 329-337, 2013.

[9] M. Reig, Z. Mariño, C. Perelló et al., "Unexpected high rate of early tumor recurrence in patients with HCV-related HCC undergoing interferon-free therapy," Journal of Hepatology, vol. 65, no. 4, pp. 719-726, 2016.

[10] F. Conti, F. Buonfiglioli, A. Scuteri et al., "Early occurrence and recurrence of hepatocellular carcinoma in HCV-related cirrhosis treated with direct-acting antivirals," Journal of Hepatology, vol. 65, no. 4, pp. 727-733, 2016.

[11] S. Pol, "Lack of evidence of an effect of Direct Acting Antivirals on the recurrence of hepatocellular carcinoma: The ANRS collaborative study group on hepatocellular carcinoma (ANRS CO22 HEPATHER, CO12 CIRVIR and CO23 CUPILT cohorts)," Journal of Hepatology, vol. 65, no. 4, pp. 734-740, 2016.

[12] C. Cammà, G. Cabibbo, and A. Craxì, "Direct antiviral agents and risk for HCC early recurrence: much ado about nothing," Journal of Hepatology, vol. 65, no. 4, pp. 861-862, 2016.

[13] H. A. Torres, J. N. Vauthey, M. P. Economides, P. Mahale, and A. Kaseb, "Hepatocellular carcinoma recurrence after treatment with direct-acting antivirals: first, do no harm by withdrawing treatment," Journal of Hepatology, vol. 65, no. 4, pp. 862-864, 2016.

[14] J.-C. Nault and M. Colombo, "Hepatocellular carcinoma and direct acting antiviral treatments: controversy after the revolution," Journal of Hepatology, vol. 65, no. 4, pp. 663-665, 2016.

[15] J. Hengst, V. Schlaphoff, K. Deterding et al., "DAA-induced $\mathrm{HCV}$ clearance does not restore the altered cytokine and chemokine milieu in patients with chronic hepatitis C," Journal of Hepatology, vol. 64, no. 2, pp. S417-S418, 2016.

[16] A. F. Carlin, P. Aristizabal, Q. Song et al., “Temporal dynamics of inflammatory cytokines/chemokines during sofosbuvir and ribavirin therapy for genotype 2 and 3 hepatitis C infection," Hepatology, vol. 62, no. 4, pp. 1047-1058, 2015.

[17] B. Martin, N. Hennecke, V. Lohmann et al., "Restoration of HCV-specific CD8+ T cell function by interferon-free therapy," Journal of Hepatology, vol. 61, no. 3, pp. 538-543, 2014.

[18] F. L. van de Veerdonk and A. M. G. Netea, "Diversity: a hallmark of monocyte society," Immunity, vol. 33, no. 3, pp. 289-291, 2010.

[19] M. A. Caligiuri, "Human natural killer cells," Blood, vol. 112, no. 3, pp. 461-469, 2008.

[20] G. Ning, L. She, L. Lu et al., "Analysis of monocytic and granulocytic myeloid-derived suppressor cells subsets in patients with hepatitis c virus infection and their clinical significance," BioMed Research International, vol. 2015, Article ID 385378, 8 pages, 2015.

[21] B. Oliviero, S. Varchetta, E. Paudice et al., "Natural killer cell functional dichotomy in chronic hepatitis $\mathrm{B}$ and chronic hepatitis C virus infections," Gastroenterology, vol. 137, no. 3, pp. 1151-1160.e7, 2009. 
[22] G. Ahlenstiel, R. H. Titerence, C. Koh et al., "Natural killer cells are polarized toward cytotoxicity in chronic hepatitis $\mathrm{C}$ in an interferon-alfa-dependent manner," Gastroenterology, vol. 138, no. 1, pp. 325.e2-335.e2, 2010.

[23] P. Bonorino, M. Ramzan, X. Camous et al., "Fine characterization of intrahepatic NK cells expressing natural killer receptors in chronic hepatitis B and C,' Journal of Hepatology, vol. 51, no. 3, pp. 458-467, 2009.

[24] B. Edlich, G. Ahlenstiel, A. Z. Azpiroz et al., "Early changes in interferon signaling define natural killer cell response and refractoriness to interferon-based therapy of hepatitis $\mathrm{C}$ patients," Hepatology, vol. 55, no. 1, pp. 39-48, 2012.

[25] G. Ahlenstiel, B. Edlich, L. J. Hogdal et al., "Early changes in natural killer cell function indicate virologic response to interferon therapy for hepatitis C," Gastroenterology, vol. 141, no. 4, pp. 1231-1239.e2, 2011.

[26] M. Spaan, G. Van Oord, K. Kreefft et al., "Immunological analysis during interferon-free therapy for chronic Hepatitis $\mathrm{C}$ virus infection reveals modulation of the natural killer cell compartment," Journal of Infectious Diseases, vol. 213, no. 2, pp. 216-223, 2016.

[27] E. Serti, X. Chepa-Lotrea, Y. J. Kim et al., "Successful interferonfree therapy of chronic hepatitis $\mathrm{C}$ virus infection normalizes natural killer cell function," Gastroenterology, vol. 149, no. 1, pp. 190-200.e2, 2015.

[28] G. Szabo, S. Chang, and A. Dolganiuc, "Altered innate immunity in chronic hepatitis C infection: cause or effect?" Hepatology, vol. 46, no. 4, pp. 1279-1290, 2007.

[29] J. Zheng, H. Liang, C. Xu et al., "An unbalanced PD-L1/CD86 ratio in $\mathrm{CD} 14++\mathrm{CD} 16+$ monocytes is correlated with $\mathrm{HCV}$ viremia during chronic HCV infection," Cellular and Molecular Immunology, vol. 11, no. 3, pp. 294-304, 2014.

[30] M. T. Bility, K. Nio, F. Li et al., "Chronic hepatitis C infection-induced liver fibrogenesis is associated with M2 macrophage activation," Scientific Reports, vol. 6, article 39520, 2016.

[31] M. Gambato, N. Caro-Pérez, P. González et al., "Neutrophil and Monocyte function in patients with chronic hepatitis $\mathrm{C}$ undergoing antiviral therapy with regimens containing protease inhibitors with and without interferon," PLoS ONE, vol. 11, no. 11, Article ID e0166631, 2016. 


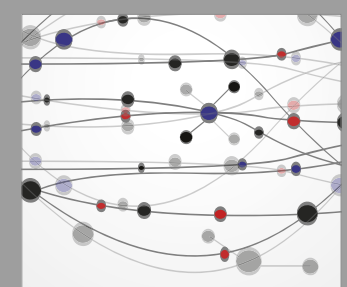

The Scientific World Journal
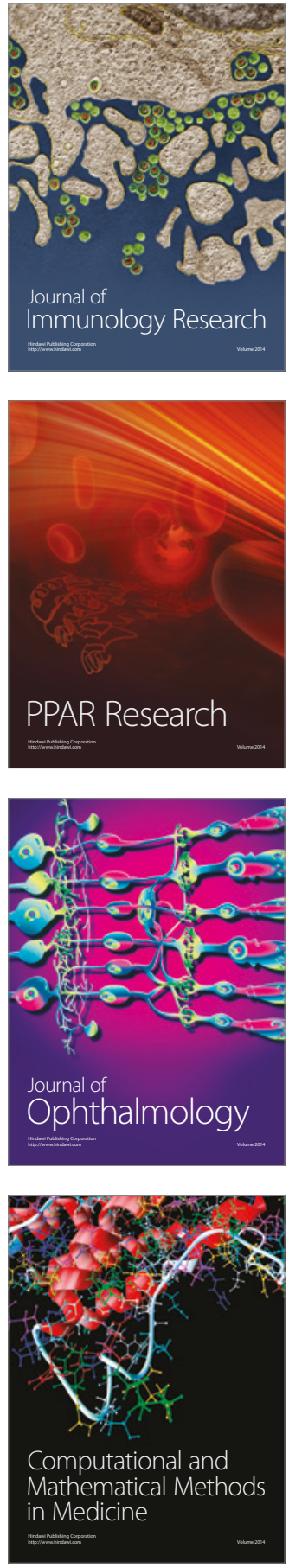

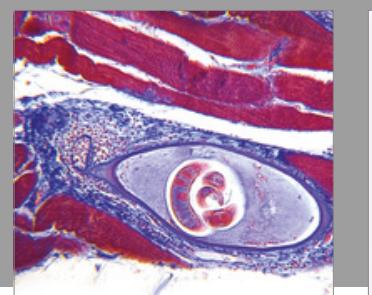

Gastroenterology Research and Practice
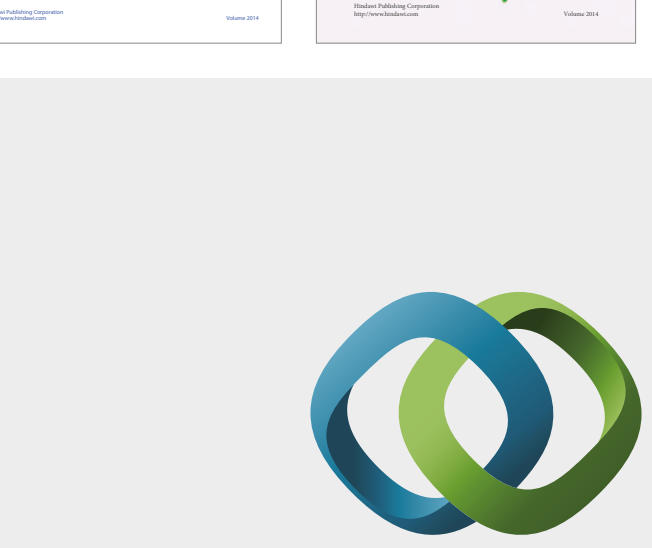

\section{Hindawi}

Submit your manuscripts at

https://www.hindawi.com
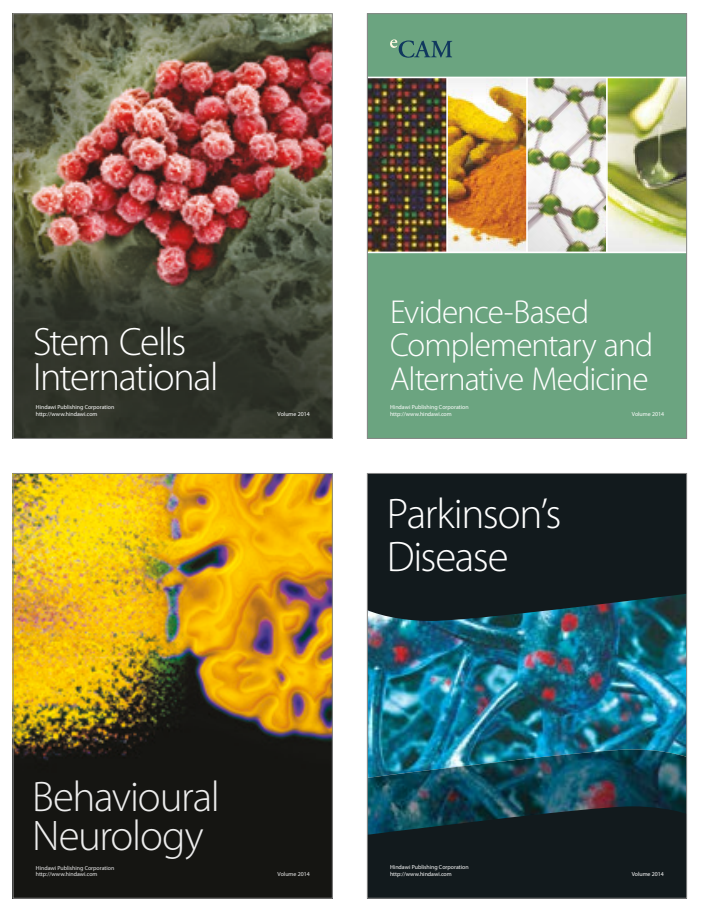
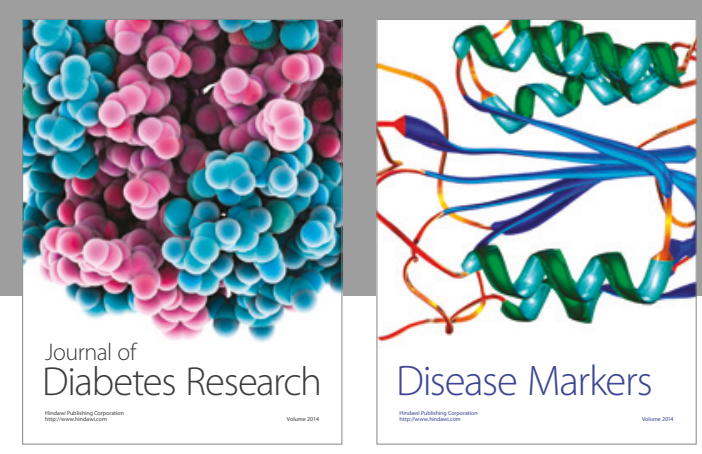

Disease Markers
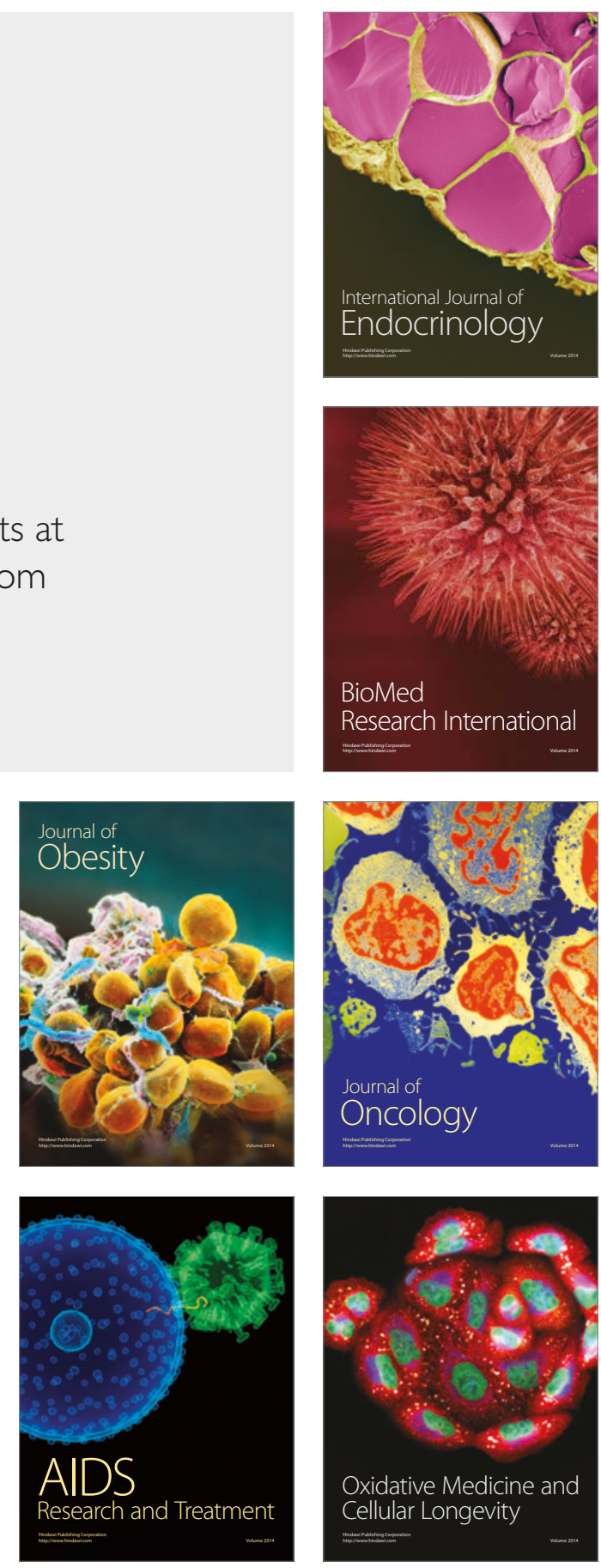